\title{
Two Heat Pipe Type High Efficient Adsorption Icemakers for Fishing Boats
}

\author{
Z.Z. Xia, R.Z. Wang*, Z.S. Lu and L.W. Wang
}

Institute of Refrigeration \& Cryogenics, Shanghai Jiao Tong University, Shanghai 200030, China

\begin{abstract}
The adsorption performances of compound adsorbent (the mixing of activated carbon and $\mathrm{CaCl}_{2}$ by proper technology)-ammonia are studied, which shows the obviously improvement for long term stable operation of adsorption/desorption, and also the large adsorption cooling density. A multifunction heat pipe for heat transfer design in adsorber is invented to use waste heat for heating and sea water for cooling effectively and reliably. An adsorption icemaker experimental system driven by the exhausted heat from the diesel engine of fishing boats are studied, which shows the optimum average SCP (specific cooling power) and COP (coefficient of performance) for the refrigerator have reached to $770.4 \mathrm{~W} / \mathrm{kg}$ and 0.39 respectively at about $-20^{\circ} \mathrm{C}$ evaporating temperature. Based upon the studies above, a real multifunction heat pipe adsorption icemaker is then designed and built, the system is fully automatic controlled by Programmable Logic Controller (PLC). The system operation shows the capability to make flake ice for more than $20 \mathrm{~kg} / \mathrm{hr}$.
\end{abstract}

\section{INTRODUCTION}

Adsorption refrigeration systems present the advantages of being absolutely benign for the environment and having zero ozone depletion potential (ODP) as well as zero global warming potential (GWP). Adsorption refrigeration is also attractive for the efficient use of solar energy and low-grade waste heat. In the last two decades, adsorption refrigeration has been paid a lot of attentions. Compared with the existing absorption systems and vapor compression refrigeration systems, the advantages of adsorption systems are less vibration, simple control, low initial investment and expenditure, and less noise (Wang, et al. 2002, Wang, et al. 2003) [1,2].

Adsorption working pairs for adsorption refrigeration include physical adsorption working pairs, chemical adsorption working pairs and compound adsorption working pairs. The researches on physical adsorption working pairs mainly focus on the application of solar energy, such as activated carbon-ammonia and activated carbon-methanol for solar refrigeration systems, silica gel-water and zeolite-water for solar air-conditioning. Typical studies are those of TamainotTelto et al. (1997) [3], Critoph et al. (1986) [4], Pralon et al. (2000) [5], Wang et al. (2003) [6], Critoph et al. (2004) [7], Lu et al. (2004) [8] and so on. The merit of chemical adsorbents is largely in their adsorptive capacity. The defects of chemical adsorbents are critical problems of heat transfer and gas permeability, as well as the problems of expansion and agglomeration (Wang, 2004) [9]. Compound adsorbents have the advantages of both porous medium and chemical adsorbent. Mauran et al. (1996) [10] studied the graphite-chemical compound adsorbents, and results show that compound adsorbent could improve the heat and mass transfer performance significantly. Wang et al. (2004) [11], Lu et al. (2006) [12] and Wang et al. (2006) [13] have researched in the consolidated compound adsorbent, which is composed of calcium chloride and activated

*Address correspondence to this author at the Institute of Refrigeration \& Cryogenics, Shanghai Jiao Tong University, Shanghai 200030, China; Tel/Fax: +(86-21) 34206548; E-mail: rzwang@sjtu.edu.cn carbon, and the results show that consolidated compound adsorbent could improve the mass transfer performance and specific volume cooling quantity of adsorbent greatly.

Various methods are used to improve the performance of adsorption refrigeration systems. For example finned tubes, plate heat exchanger, heat pipe theory, etc are used in the design of adsorption beds to improve mass and heat transfer performance. Wang et al. (2002) [14] incorporated heat and mass recovery processes into the continuous cycle. Most of the advanced cycles have been proposed with the purpose of achieving either high $C O P$ or $S C P$ values. Based on the outstanding work of the previous researchers, this paper presents the design and experiment of a product of a multifunction heat pipe adsorption experimental refrigerator and an ice-maker for fishing boat, which is driven by waste heat from exhaust gases and its effect on the system performance is analyzed. $\mathrm{CaCl}_{2} /$ activated carbon is used as compound adsorbent, ammonia as adsorbate.

\section{COMPOUND ADSORBENT}

Adsorber is the most important part in the adsorption refrigeration system. In this system, the adsorber is designed as (Fig. 1). There are 19 finned tubes and 12 vapordistributing tubes in each adsorber.

The consolidated adsorbent of $\mathrm{CaCl}_{2}$ and activated carbon is used as adsorbent, which has a high volume adsorption capacity while avoiding the problems of agglomeration and performance attenuation. Here, $\mathrm{CaCl}_{2}$ powder, coconut shell activated carbon and a small quantity of high-quality cement are mixed and compacted together in a consolidated adsorbent in that mixture, the cement acts as binder, as shown in Fig. (1-A). The mass fractions of $\mathrm{CaCl}_{2}$, activated carbon (before be purified) and cement in the consolidated compound, are in the proportion of $16: 4: 1$, respectively. The consolidated compound adsorbent is pressed inside fins, as shown in Fig. (1-B), and then the mesh and metal screen are covered in order to avoid the adsorbent leak from finned tubes, as shown in Fig. (1-C). At last, these tubes are welded between the cover plates in the adsorber, as shown in Fig. (1-D). The structure of the adsorber is shown as Fig. (1-E). 


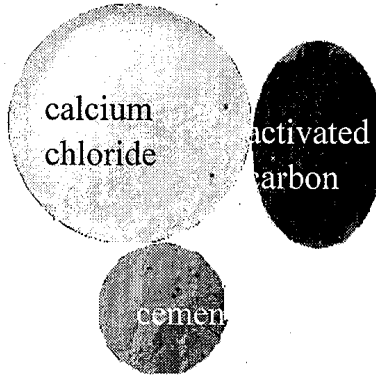

$1-\mathrm{A}$

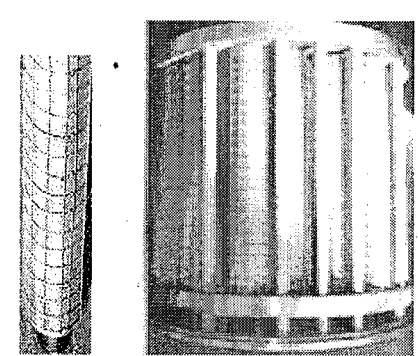

$1-\mathrm{C}$

$1-\mathrm{D}$

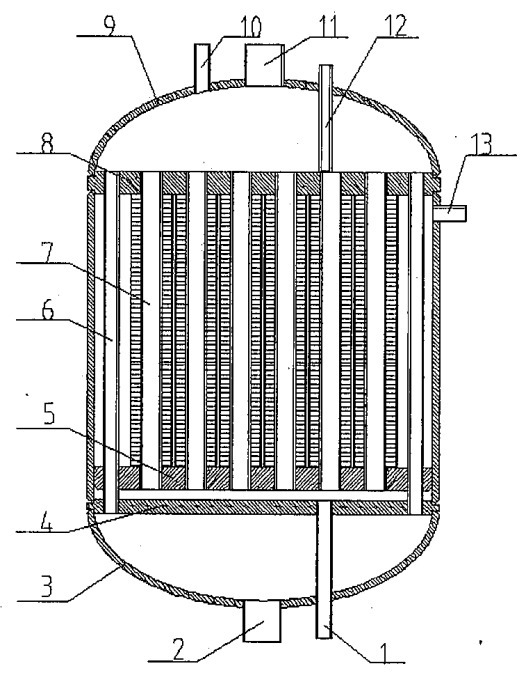

$1-E$

Fig. (1). Manufacture of the adsorber (1-A: The composition of compound adsorbent, 1-B: The compound adsorbent was pressed between the aluminum fins, 1-C: The mesh and metal screen are covered over the aluminum fins, 1-D: The insider of the adsorber, 1-E: The structure of the adsorber).

1 heat pipe liquid pipeline, 2 heat pipe vapor pipeline, 3 end plate 1 , 4 cover plate 1, 5 cover plate 2, 6 vapor distributing tubes, 7 finned tubes, cover plate 3,9 end plate 2, 10 heat recovery pipeline, 11 heat pipe vapor pipeline, 12 temperature sensor, 13 ammonia pipeline.

\section{MULTIFUNCTION HEAT PIPE ADSORPTION RE- FRIGERATION SYSTEM}

There are four main processes in the work of this system. They are the processes of heat pipe heating, heat pipe cooling, mass recovery and heat pipe heat recovery.

1) The process of heat pipe heating: The heating boiler serves as the evaporating part of heat pipe; adsorber serves as condensing part of heat pipe. The heat pipe liquid is heated by the heating boiler and then evaporates, the vapor then enters the adsorber through the vapor-distributing tubes, and condenses inside the finned tubes in adsorber to provide desorption heat. At last the heat pipe liquid returns to the heating boiler to be heated again.

2) The process of heat pipe cooling: Before this process, the hot adsorber is connected to the cooler. As a result, the pressure prevailing therein is lower than that in the boiler. So, the heat pipe liquid can easily be pumped from the liquid pumping boiler into the adsorber.

During the process of heat pipe cooling, the hot adsorber serves as the evaporating part of heat pipe; cooler serves as condensing part of heat pipe. The heat pipe liquid evaporates in the adsorber, bring the adsorption heat out of adsorber, then enters the cooler and condenses in the cooler, the condensed liquid then returns to the adsorber again.

3) The process of mass recovery: The mass recovery process utilizes the pressure difference to enhance the refrigerant mass circulation. In mass recovery process, the valve between the hot adsorber and the cold adsorber is opened, and the ammonia vapor in the hot adsorber will enter the cold one quickly.

4) The process of heat pipe heat recovery: In the process of heat pipe heat recovery, the hot adsorber serves as the evaporating part of heat pipe while the cold adsorber serves as condensing part of heat pipe. The heat pipe liquid evaporates in the hot adsorber, then enters the clod adsorber, condensing there and transferring heat from hot adsorber to the cold adsorber, then the heat pipe liquid returns to hot adsorber again. Thus heat pipe heat recovery circuit is formed.

\section{ADSORPTION REFRIGERATION EXPERIMEN- TAL SYSTEM}

The average cooling power is calculated by the liquid level changes measured from the level sensor. The adsorption quantity is tested by the magnetostriction level sensor inside evaporator with relative measuring error of less than $0.05 \%$. The diameter of evaporator is given, that is $117 \mathrm{~mm}$.

The averaged $S C P$ is:

$S C P=1000 \frac{h_{f g a} \rho_{l} V_{l}}{m \cdot t}$

Where $S C P$ is in $(\mathrm{W} / \mathrm{kg}), m$ is the mass of $\mathrm{CaCl}_{2}$ in compound adsorbent for each adsorber $(1.88 \mathrm{~kg}), h_{f g a}$ is the latent heat of vaporization at evaporation temperature of ammonia $(\mathrm{kJ} / \mathrm{kg}), \rho_{l}$ is fluid density of ammonia at evaporation temperature $\left(\mathrm{kg} / \mathrm{m}^{3}\right), V_{l}$ is the evaporated liquid volume of ammonia for the phase of adsorption $\left(\mathrm{m}^{3}\right)$, and $t$ is the corresponding adsorption time ( $\mathrm{s})$. The coefficient of cooling performance is:

$C O P=\frac{h_{f g a} \rho_{l} V_{l}}{\left(t-t_{r}\right) w_{k}}$

Where COP is the coefficient of performance; $t$ cycle time $(\mathrm{s}) ; t_{r}$ the time of heat and mass recovery $(\mathrm{s}) ; w_{h}$ heat power $(\mathrm{kW})$ 


\subsection{System Design}

The multifunction adsorption system is shown in Fig. (2), which is mainly composed of a liquid pumping boiler, a heating boiler, two coolers, two adsorbers, a condenser, and an evaporator. This system was originally developed as an adsorption ice-maker for fishing boats, in which the waste heat from the exhausted gases of diesel engine can be used to heat the adsorber, and the sea water can be used to cool the adsorber. As steel adsorber is used for compound adsorbentammonia, the exhausted gases and also the sea water can not be used for direct heating and cooling. By proper design of a heat pipe unit, heating or cooling of the adsorber is via the heat pipe working substances, such as water and acetone etc.

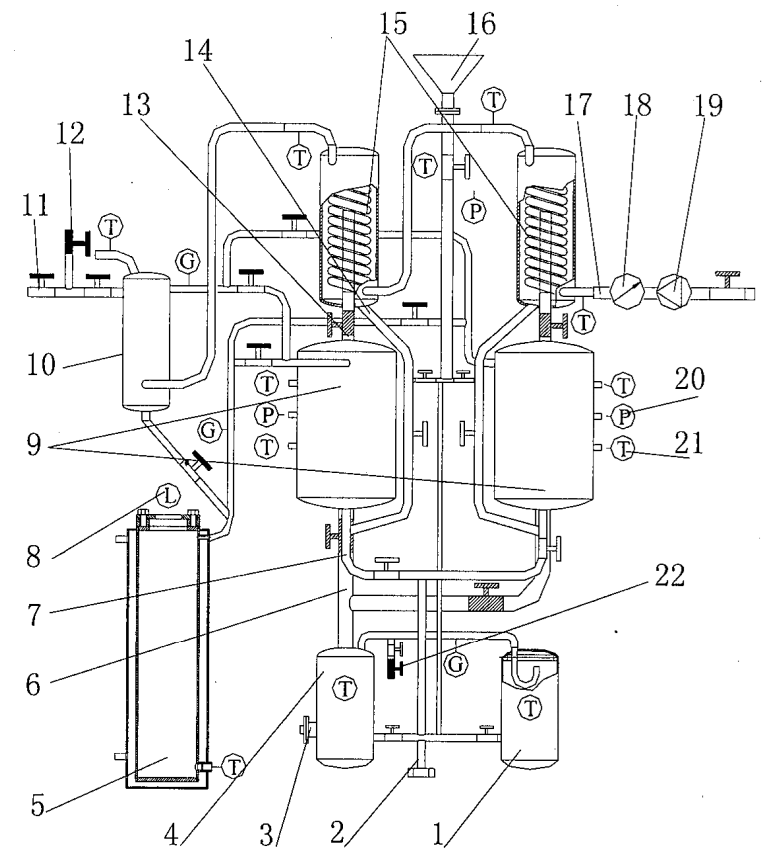

Fig. (2). Structure of the refrigeration system. 1-Liquid pumping boiler; 2-tap-hole; 3-electric heater; 4-heating boiler; 5-evaporator; 6-vapour pipeline; 7-liquid pipeline; 8-magnetostriction level sensor; 9-adsorbers; 10-condenser; 11-ammonia inlet; 12-safety valve; 13- vapour pipeline; 14-liquid pipeline; 15-coolers; 16-aspirating hole and heat pipe liquid inlet; 17-cooling water pipeline; 18-water meter;19-cooling water pump; 20- pressure sensor; 21-temperature sensor; 22-safety valve.

\subsection{The Clausius-Clapeyron of Different Cycles in the First Experimental Test Unit}

The working condition of mass recovery is: water heat pipe, 40 seconds of mass recovery time, 70 minutes of cycle time, $3.64 \mathrm{~kW}$ of heating power, about $110^{\circ} \mathrm{C}$ of desorption temperature, $-15{ }^{\circ} \mathrm{C}$ of evaporating temperature, $30{ }^{\circ} \mathrm{C}$ of cooling water temperature. And the working condition of heat pipe heat recovery is: water heat pipe, 40 -second mass recovery, 70 minutes of cycle time, $3.64 \mathrm{~kW}$ of heating power, $-20^{\circ} \mathrm{C}$ of evaporating temperature, $20^{\circ} \mathrm{C}$ of cooling water temperature, 2 minutes of heat recovery.

The Clausius-Clapeyron diagrams of the basic cycle, the cycle with mass recovery and the cycle with mass-heat recovery are shown in Fig. (3), Fig. (4) and Fig. (5), respectively.

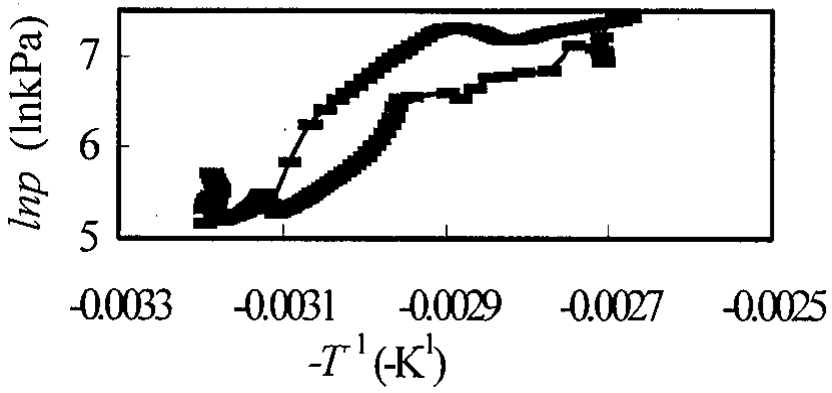

Fig. (3). Clausius-Clapeyron of the basic cycle.

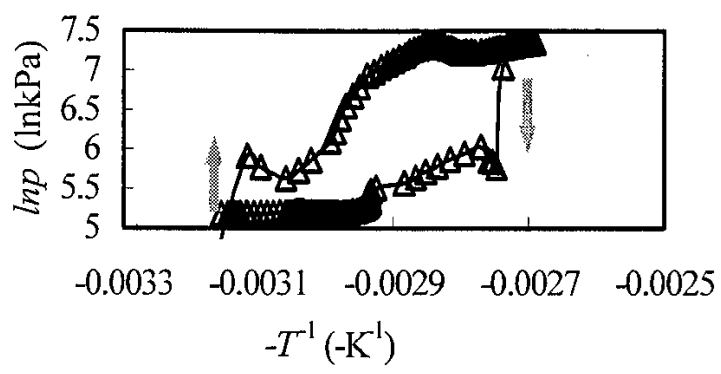

Fig. (4). Clausius-Clapeyron with mass recovery.

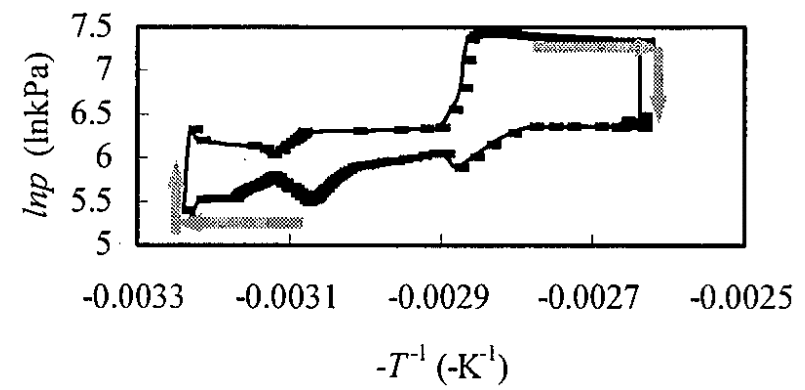

Fig. (5). Clausius-Clapeyron with mass-heat recovery.

By comparison of the Fig. (3) and Fig. (4), it can be shown that in adsorption phase, it can be seen that after the mass recovery, the pressure of the hot bed and the cold bed will attain the same median value. During the mass recovery, much ammonia vapor enters the cold adsorber from the hot adsorber. So, the cycle adsorptive capacity is improved.

By comparison of the Fig. (4) and Fig. (5), it can be shown that after the combined mass-heat recovery, the desorber temperature and the adsorber temperature can be extended to a higher value and a lower value, respectively, because the adsorbers are pre-heated and pre-cooled, respectively, during the mass-heat recovery.

\subsection{The Refrigeration Performance Variation With Dif- ferent Cooling Water Temperature (Measured by Am- monia Evaporation Capacity)}

This novel design of multifunction heat pipe type adsorption ice-maker is considered for possible application in fishing boats, and the normal fishing period is from January to June and from September to November and corresponding seawater temperature is about from $15^{\circ} \mathrm{C}$ to $30^{\circ} \mathrm{C}$. Adsorber temperature falls down with the cooling water temperature. In water heat pipe adsorption ice-maker, the adsorption icemaker refrigeration performance with mass and heat pipe heat recovery for fishing boats is studied. The working con 
Table 1. Averaged $S C P$ Variation with Different Cooling Water Temperature

\begin{tabular}{|c|c|c|c|c|}
\hline Cooling water temp. $\left({ }^{\mathbf{0}} \mathbf{C}\right)$ & Evapora. temp. $\left({ }^{\circ} \mathbf{C}\right)$ & Desorpt. temp. $\left({ }^{\mathbf{0}} \mathbf{C}\right)$ & SCP $(\mathbf{W} / \mathbf{k g})$ & COP \\
\hline \hline 20 & -21.3 & 114.7 & 670.4 & 0.39 \\
\hline 25 & -18.1 & 114.0 & 676.8 & 0.34 \\
\hline 30 & -19.4 & 113.7 & 528.0 & 0.26 \\
\hline
\end{tabular}

dition is: 70-minute cycle time, 40 -second mass recovery; 2 minute heat recovery; about $-20^{\circ} \mathrm{C}$ evaporating temperature, $15 \sim 30^{\circ} \mathrm{C}$ cooling water temperature.

The performance of adsorption refrigeration is shown in Table 1, which shows that the averaged $S C P$ and the $C O P$ increase when the temperature of cooling water decreases. But at the condition of highest temperature of cooling water of $30^{\circ} \mathrm{C}$, the averaged $S C P$ and the $C O P$ is still as high as $528 \mathrm{~W} / \mathrm{kg}$ and 0.26 , respectively.

\section{MULTIFUNCTION HEAT PIPE ADSORPTION ICEMAKER SYSTEM}

The second adsorption icemaker system aims at improving the performance of adsorption refrigeration by applying three-dimensional finned tubes to enhance heat transfer and PLC for autocontrol. Moreover, many experiments have been done to analyze the influence of operating conditions (cooling water temperature, mass recovery and heat pipe heat recovery, etc) on the mass of ice, $S C P$ and $C O P$.In this experiment, the adsorber is heated by electric heater, and the temperature of the cooling water is controlled by the constant temperature cabinet.
The performance parameters of this system are the specific cooling power $(S C P)$ and the coefficient of performance $(C O P)$. They can be measured by the following formulas:

The average $S C P$ is calculated by the formula (3):

$$
S C P=1000 \frac{m_{w} C_{w} T_{i n}+m_{w} \lambda+m_{w} C_{i}\left(T_{s}-T_{i}\right)}{m_{a} \cdot t}
$$

Where $S C P$ is at $(\mathrm{W} / \mathrm{kg}), m_{w}$ is the mass of the ice $(\mathrm{kg}), C_{w}$ is the specific heat of water $\left(\mathrm{kJ} / \mathrm{kg} .{ }^{\circ} \mathrm{C}\right), T_{\text {in }}$ is the inlet temperature of the chilled water $\left({ }^{\circ} \mathrm{C}\right), \lambda$ is the heat of solidification of water $(\mathrm{kJ} / \mathrm{kg}), C i$ is the specific heat of ice $\left(\mathrm{kJ} / \mathrm{kg} .{ }^{\circ} \mathrm{C}\right), T_{s}$ is freezing temperature $\left({ }^{\circ} \mathrm{C}\right), T_{i}$ is the ice temperature $\left({ }^{\circ} \mathrm{C}\right), t$ is the half cycle time (s), $m_{a}$ is the mass of the adsorbent in each adsorber $(\mathrm{kg})$.

The coefficient of cooling performance $(C O P)$ is calculated by the formula (4):

$C O P=\frac{m_{w} C_{w} T_{i n}+m_{w} \lambda+m_{w} C_{i}\left(T_{s}-T_{i}\right)}{\int w_{h} d t}$

Where $C O P$ is the coefficient of performance, $w_{h}$ is heating power $(\mathrm{kW}), t$ is heating time $(\mathrm{s})$.
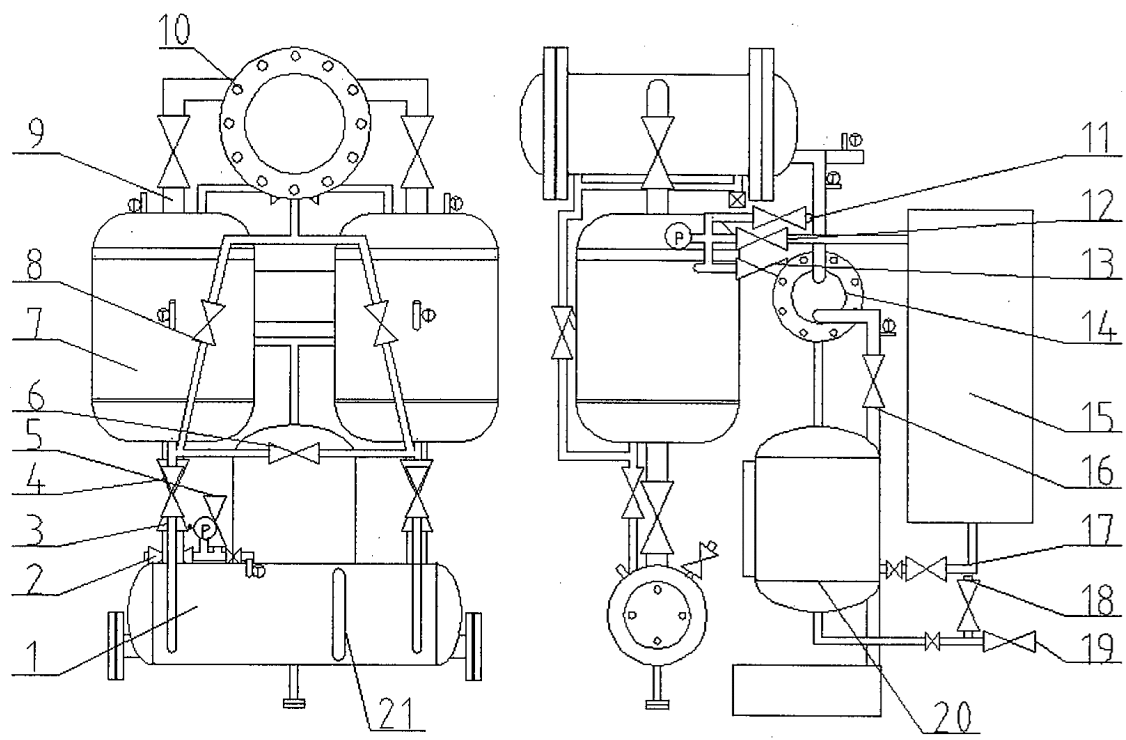

Fig. 6-A

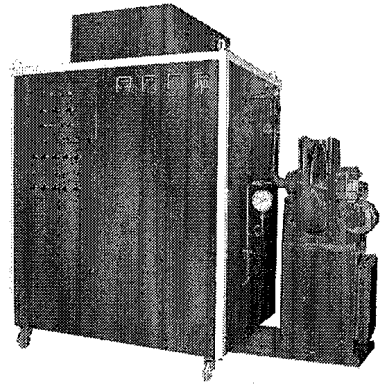

Fig. 6-B

Fig. (6). The photos of adsorption icemaker system (6- A:schematic diagram, 6-B:photo of the system).

1 heating boiler, 2 prefill valve for heat pipe liquid (water) , 3 heating vapor pipeline, 4 heating liquid pipeline, 5 safety valve for boiler, 6 heat pipe heat recovery pipeline, 7 adsorber, 8 cooling liquid pipeline, 9 cooling vapor pipeline, 10 cooler, 11 mass recovery pipeline, 12 pipeline for adsorption, 13 pipeline for desorption, 14 condenser, 15 flake icemaker, 16 pipeline for cooling water, 17 ammonia restrictive valve, 18 safety valve for condenser, 19 prefill valve for ammonia, 20 ammonia liquid receiver, 21 viewing mirror for boiler 
This system is shown in Fig. (6), which consists of six main parts: one boiler, two adsorbers, one cooler, one condenser, one ammonia storage tank and one ice-maker.

\subsection{Adsorption Performance Variation With Different Mass Recovery}

The icemaker with mass recovery process utilizes the pressure difference to enhance the refrigerant mass circulation. As it is shown in our previous publication, mass recovery can not only improve the adsorption refrigeration performance significantly, but can also recover much of heat of adsorption. The inlet and outlet water temperatures of condenser are studied, as shown in Fig. (7). During the mass recovery, the high temperature ammonia vapor has entered the low pressure adsorber. So, from the Fig. (7), we can see that the outlet water temperature with mass recovery is lower than that without mass recovery. By the calculation of the formula (5), the cooling power of the condenser can be reduced by $28.4 \%$ after 40 seconds of mass recovery.

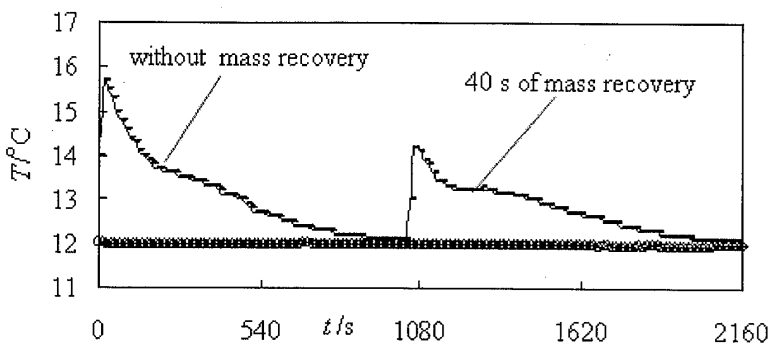

Fig. (7). The inlet/outlet water temperature of the condenser.

$q_{r}=m_{r} C_{r}\left(T_{r o}-T_{r i}\right)$

Where $q_{r}$ is the cooling power (kW), $m_{r}$ is the mass flow of cooling water $(\mathrm{kg} / \mathrm{s}), C_{r}$ is the specific heat of water $\left(\mathrm{kJ} / \mathrm{kg} .{ }^{\circ} \mathrm{C}\right), T_{r o}$ is the outlet water temperature $\left({ }^{\circ} \mathrm{C}\right), T_{r i}$ is the inlet water temperature $\left({ }^{\circ} \mathrm{C}\right)$.

The performance of the mass recovery varies with the mass recovery time. If the time is too short, the mass of the ammonia can not be recovered adequately. Otherwise, when the time is too long, the time for adsorption/desorption will be shortened relatively. Reference (Akahira et al. 2004) [15] shows that the more cooling capacity can be obtained by applying heating and cooling in mass recovery process. The continuation of heating and cooling increases a quantity of ammonia vapor moving from desorber to adsorber, which will lead the system to provide better cooling capacity.

In this experiment, the adsorption performance variation with different mass recovery is studied, as shown in Table $\mathbf{2}$.
Table 2 shows the adsorption refrigeration performance of the cycle with $40 \mathrm{~s}$ of mass recovery with heating and cooling is the better than the others.

\subsection{Adsorption Performance Variation With Different Heat Pipe Heat Recovery}

The heat pipe heat recovery can bring about two merits. Firstly, by heat pipe heat recovery, much heat can be recovered. Secondly, after the process of heat pipe cooling, the adsorber is heated for desorption and water in the adsorber is discharged to boiler, that will descend boiler water temperature. Boiler water temperature of the cycle with heat pipe heat recovery is higher than that without heat recovery, because water is preheated by the process of heat pipe heat recovery.

In this experiment, the adsorber temperature variation with different heat pipe heat recovery time is shown in Fig. (8), which shows that the 2 minutes of the heat recovery is the better choice than the others. By 2 minutes of the heat pipe heat recovery, the adsorber temperature can reach a lower value during the cooling phase and it can get a higher temperature during the heating phase.

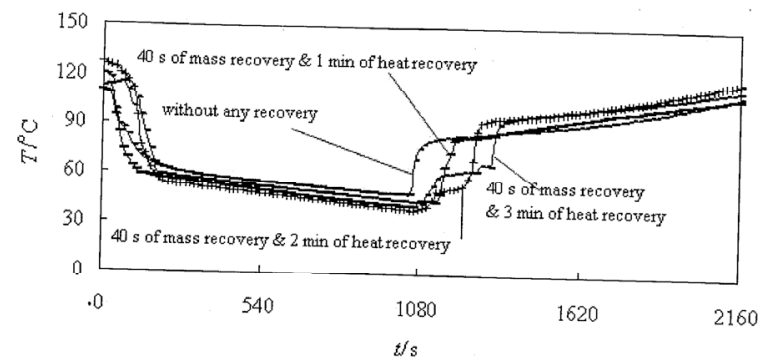

Fig. (8). The adsorber temperature variation with different heat pipe heat recovery time.

The adsorption performance of the icemaker with different heat recovery time is shown in Table $\mathbf{3}$. The adsorption performance variation with different sea water temperature is shown in Table 4, which shows that the average $S C P$ and $C O P$ increase as the temperature of cooling water decreases.

\section{CONCLUSIONS}

In the first experimental test unit, the multifunction heat pipe adsorption system is designed and established, and dynamic characteristics of mass and heat pipe heat recovery are analysed. Then a real multifunction heat pipe adsorption icemaker is designed and built. Several conclusions obtained are as follows:

Table 2. The Performance Variation with Different Mass Recovery (The Ice Temperature is About $-\mathbf{7 . 5}^{\circ} \mathrm{C}$; The Desorption Temperature of the Absorber is About $126^{\circ} \mathrm{C}$ and the Adsorption Temperature of the Adsorber is About $38{ }^{\circ} \mathrm{C}$ )

\begin{tabular}{|c|c|c|c|c|c|}
\hline Mass recovery (s) & Heat recovery(min) & Cycle time (min) & Mass of ice(kg/h) & $\boldsymbol{S C P}(\mathbf{W} / \mathbf{k g})$ & \multicolumn{1}{|c|}{$\boldsymbol{C O P}$} \\
\hline \hline 20 & 2 & 36 & 22.9 & 429.8 \\
\hline 40 & 2 & 36 & 25.4 & 476.1 & 0.3 \\
\hline 40 (with heating \&cooling) & 2 & 36 & 26.1 & 494.5 \\
\hline 60 & 2 & 36 & 24.3 & 456.3 \\
\hline
\end{tabular}


Table 3. The Adsorption Performance of the Icemaker with Different Heat Recovery Time $\left(12^{\circ} \mathrm{C}\right.$ of the Cooling Water Temperature, and $-7.5^{\circ} \mathrm{C}$ of the Ice Temperature)

\begin{tabular}{|c|c|c|c|c|c|}
\hline 1 & 40 & 36 & 19.8 & 377.6 & 0.2 \\
\hline 3 & 40 & 36 & 21.5 & 407.6 & 0.2 \\
\hline
\end{tabular}

Table 4. The Adsorption Performance Variation with Different Sea Water Temperature (The Ice Temperature is About $-7.5{ }^{\circ} \mathrm{C}$ )

\begin{tabular}{|c|c|c|c|c|c|}
\hline Cooling water $\left({ }^{\circ} \mathrm{C}\right)$ & Heat recovery(min) & Mass recovery(s) (with heating and cooling) & Mass of ice(kg/h) & $S C P(\mathbf{W} / \mathbf{k g})$ & COP \\
\hline 27 & 2 & 40 & 14.8 & 324.6 & 0.2 \\
\hline 17 & 2 & 40 & 22.2 & 443.0 & 0.3 \\
\hline 12 & 2 & 40 & 26.1 & 494.5 & 0.3 \\
\hline
\end{tabular}

1) The process of mass recovery can not only improve the adsorption performance, but can also recover much of heat of adsorption.

2) The process of heat pipe heat recovery can recover much of heat. During this process, the hot adsorber is pre-cooled and the cold adsorber is preheated.

3) The adsorption performance varies with different sea water temperature. The average $S C P$ and $C O P$ increase as the temperature of cooling water decreases. In the first experimental test unit, At the condition of highest temperature of cooling water of $30{ }^{\circ} \mathrm{C}$, lowest averaged $S C P$ and $C O P$ are still as high as $528 \mathrm{~kg} / \mathrm{kg}$ and 0.26 , respectively. In the real icemaker system, when the sea water is about from $27^{\circ} \mathrm{C}$ to $12^{\circ} \mathrm{C}$, the $S C P$ varies from $324.6 \mathrm{~W} / \mathrm{kg}$ to $494.5 \mathrm{~W} / \mathrm{kg}$ and the $C O P$ varies 0.2 to 0.3 , respectively.

\section{ACKNOWLEDGEMENTS}

This work was supported by National Science Fund for Distinguished Young Scholars of China under the contract No. 50225621, Shanghai Shuguang Training Program for the Talents under the contract No. 02GG03 ,. Natural Science Fund of Shanghai City under the contract No. 05ZR14072. The authors thank Mr.Y.X. Xu for helping to install the experimental setup.

\section{REFERENCES}

[1] R. Z. Wang, J. Y. Wu, Y. J. Dai, Z. S. Jiang, W. Wang, Adsorption Refrigeration. China Machine Press, 2002.

[2] L. W. Wang, R. Z. Wang, Y. X. Xu, S. G. Wang, "Experimental study of a solidified activated carbon-methanol adsorption ice maker.", Appl. Therm. Eng., Vol. 23, pp. 1453-1462, 2003.

[3] Z. Tamainot, R. E. Critoph, "Adsorption refrigerator using mono- lithic carbon-ammonia pair", Int. J. Refrig., Vol. 20, pp.146-155, 1997.

[4] R. E. Critoph, R. Vogel, "Possible adsorption pairs for use in solar cooling", Ambient Energy, Vol. 7, pp. 183-190, 1986.

[5] A. Pralon, F. Leite, M. Daguenet, "Performance of a new solid adsorption ice maker with solar energy regeneration", Energy Convers Manage, Vol. 41, pp. 1625-1647, 2000.

[6] S. G. Wang, R. Z. Wang, J. Y. Wu, Y. X. Xu, "Experimental results and analysis for adsorption ice-making system with consolidated adsorbent", Adsorption, Vol. 9, pp. 349-358, 2003.

[7] R. E. Critoph, S. J. Metcalf, "Specific cooling power intensification limits in ammonia-carbon adsorption refrigeration systems", Appl. Therm. Eng., Vol. 24, pp. 661-678, 2004..

[8] Y. Z. Lu, R. Z. Wang, S. J. Zhou, M. Zhang, Y. X. Xu, J. Y. Wu, "Performance of a diesel locomotive waste-heat-powered adsorption air conditioning system", Adsorption, Vol. 10, pp. 57-68, 2004.

[9] L. W. Wang, R. Z. Wang, J. Y. Wu, "The performance study of the application of adsorption refrigeration using calcium chlorideammonia working pair”, Sci. China Ser., Vol. 34, pp. 268-279, 2004.

[10] S. Mauran, O. Coudevylle, H. B. Lu, "Optimization of porous reactive media for solid sorption heat pumps", in the Proceedings of International Absorption Heat Pump Conference, pp. 3-8, 1996.

[11] L. W. Wang, R. Z. Wang, J. Y. Wu, K. Wang, S. G. Wang, "Adsorption ice makers for fishing boats driven by the exhaust heat from diesel engine: choice of adsorption pair". Energy Convers Manage, Vol. 45, pp. 2043-2057, 2004.

[12] Z. S. Lu, R. Z. Wang, L. W. Wang, C. J. Chen, "Performance analysis of an adsorption refrigerator using activated carbon in a compound adsorbent", Carbon, Vol. 44, pp. 747-752, 2006.

[13] L. W. Wang, R. Z. Wang, Z. S. Lu, Y. X. Xu, J. W. Wu, "Split heat pipe type compound adsorption ice making unit for fishing boats", Int. J. Refrig., Vol. 29, pp. 456-468, 2006.

[14] W. Wang, T. F. Qu, R. Z. Wang, "Influence of degree of mass recovery and heat regeneration on adsorption refrigeration cycles", Energy Convers Manage, Vol. 43, pp. 733-741, 2002.

[15] A. Akahira, K. C. A. Alam, Y. Hamamoto, A. Akisawa, T. Kashiwagi, "Mass recovery adsorption refrigeration cycle-improving cooling capacity", Int. J. Refrig., Vol. 27, pp. 225-234, 2004. 